\title{
Gender Snapshots
}

Renée von Paschen

University of Vienna, Austria

\begin{tabular}{|c|c|}
\hline $\begin{array}{l}\text { Die a Social Death } \\
\text { by Renée von Paschen }\end{array}$ & $\begin{array}{l}\text { Der soziale Tod } \\
\text { German by Renée von Paschen }\end{array}$ \\
\hline $\begin{array}{l}\text { I may say } \\
\text { what I want, } \\
\text { but can I? }\end{array}$ & $\begin{array}{l}\text { Ich darf sagen, } \\
\text { was ich will, } \\
\text { aber kann ich? }\end{array}$ \\
\hline $\begin{array}{l}\text { I can say } \\
\text { what I want, } \\
\text { but do I? }\end{array}$ & $\begin{array}{l}\text { Ich kann sagen, } \\
\text { was ich will, } \\
\text { aber tue ich's? }\end{array}$ \\
\hline $\begin{array}{l}\text { I do say } \\
\text { what I want, } \\
\text { but may I? }\end{array}$ & $\begin{array}{l}\text { Ich sage schon, } \\
\text { was ich will, } \\
\text { aber darf ich? }\end{array}$ \\
\hline $\begin{array}{l}\text { Or will I die } \\
\text { a social death, } \\
\text { if I try? }\end{array}$ & $\begin{array}{l}\text { Oder sterbe ich } \\
\text { dafür den } \\
\text { sozialen Tod? }\end{array}$ \\
\hline Dual Disadvantage & Doppelter Nachteil \\
\hline $\begin{array}{l}\text { The dual disadvantage } \\
\text { of being a woman abroad }\end{array}$ & $\begin{array}{l}\text { Der doppelte Nachteil } \\
\text { als Frau in der Fremde. }\end{array}$ \\
\hline $\begin{array}{l}\text { Has led me to see through } \\
\text { the social fraud }\end{array}$ & $\begin{array}{l}\text { Hilft mir durchschauen } \\
\text { das Trugbild }\end{array}$ \\
\hline $\begin{array}{l}\text { Of gender equality. } \\
\text { Can't you see, too? }\end{array}$ & $\begin{array}{l}\text { Gleichberechtigter Frauen. } \\
\text { Siehst du's nicht auch? }\end{array}$ \\
\hline
\end{tabular}




\section{Crossing the Limits \\ by Renée von Paschen}

Crossing the limits

of his imagination,

Her thoughts cruise

along the highways

of his mind,

Colliding in their orbits

with the planets

of consternation,

contemplation

and condemnation.

\section{Grenzgänger}

German by Renée von Paschen

Wenn sie die Grenzen

seiner Vorstellung überschreitet,

Fahren ihre Gedanken

auf den Schienen

seines Verstands,

Stoßen auf ihren Umlaufbahnen

zusammen mit den Planeten

der Entrüstung,

Besinnung

und Verdammung.

\section{In den Abgrund}

Und wieder fällt

die Blüte

in den Abgrund.

Ohne Grund

gab sie nicht

die Hoffnung auf.

Was sie nicht

ahnen konnte,

war das schnelle

Tempo des

Verwelkens, das

sie unversehens

In ihrer Pracht

getroffen hat. 


\section{Surrounded by Cowards by Renée von Paschen}

Surrounded by cowards, who only speak up when no one's listening.

Why dare,

if someone's here?

Why debate, unless it's too late

To blend into the wall, showing no color at all?

A little hypocrisy will go a long way,

If maintaining the status quo is the game you play.

\section{Umgeben von Feiglingen}

German by Renée von Paschen

Umgeben von Feiglingen, die sich nur melden

wenn niemand zuhört.

Warum es wagen,

die Meinung zu sagen?

Warum danach fragen,

in schwierigen Lagen?

Sich lieber anpassen,

auf die anderen verlassen.

Ein wenig heucheln

hilft schon recht viel,

Willst du dich halten

in diesem Spiel.

\section{Reined In}

I refuse to be reined in

by constraints,

Or hedged up

against a wall.

If I cannot write

what I think,

Then I'd rather not

write at all.

\section{Eingeengt}

Ich lasse mich

nicht einengen

Oder in eine

Ecke drängen.

Wenn ich nicht schreiben darf, was ich denke,

Verzichte ich drauf, bevor ich mich verrenke. 


\section{Afraid of Freud \\ by Renée von Paschen}

Vienna has always

been afraid of Freud.

This pretty city

hides its skeletons

in closets,

And its daughters

in dungeons,

In abject denial

of the crucial truth.

\section{Angst vor Freud}

German by Renée von Paschen

Wien hat sich nie

über Freud gefreut.

Die schöne Stadt

versteckt ihre Leichen

im Schrank

Und ihre Töchter

im Keller,

Liebt Triebe,

hasst Wahrheit. 


\begin{tabular}{l|l}
$\begin{array}{l}\text { Amsterdam Can } \\
\text { by Renée von Paschen }\end{array}$ & $\begin{array}{l}\text { Amsterdam kann } \\
\text { übersetzt von Gerhild Krutak }\end{array}$ \\
$\begin{array}{l}\text { Amsterdam can } \\
\text { help you out of the closet. }\end{array}$ & $\begin{array}{l}\text { Amsterdam kann } \\
\text { dir helfen, dich zu outen. }\end{array}$ \\
$\begin{array}{l}\text { Amsterdam can } \\
\text { set you straight on Jewish history. }\end{array}$ & $\begin{array}{l}\text { Amsterdam kann } \\
\text { dich jüdische Geschichte lehren. }\end{array}$ \\
$\begin{array}{l}\text { Amsterdam can } \\
\text { bake you hash brownies. }\end{array}$ & $\begin{array}{l}\text { Amsterdam kann } \\
\text { dir Haschischkekse backen. }\end{array}$ \\
$\begin{array}{l}\text { Amsterdam can } \\
\text { soothe your nerves. }\end{array}$ & $\begin{array}{l}\text { Amsterdam kann } \\
\text { deine Nerven beruhigen. }\end{array}$ \\
$\begin{array}{l}\text { Amsterdam can } \\
\text { bowl you over. }\end{array}$ & $\begin{array}{l}\text { Amsterdam kann } \\
\text { dich umwerfen. }\end{array}$ \\
$\begin{array}{l}\text { Amsterdam can } \\
\text { do you in } \\
\text { or } \\
\text { it can } \\
\text { set you free. }\end{array}$ & $\begin{array}{l}\text { Amsterdam kann } \\
\text { dich } \\
\text { vernichten } \\
\text { oder } \\
\text { befreien. }\end{array}$ \\
\hline $\begin{array}{l}\text { C } 2015 \text { Renée von Paschen: The poet holds the copyrights } \\
\text { to the originals and the translations. }\end{array}$
\end{tabular}

